\title{
PROCOLLAGEN SYNTHESIS BY FRESH AND CRYOPRESERVED RAT PULMONARY VALVE GRAFTS
}

James M. Kneebone, MS

Flavian M. Lupinetti, MD
Objective: Allograft valves are frequently used in the repair of congenital cardiac anomalies. The failure rate may differ depending on the type of allograft used. Previous studies have shown that rat aortic valve grafts exhibit synthesis of procollagen, suggesting a capacity for repair and regeneration after implantation. No studies of pulmonary valve grafts in the heterotopic rat implant model have thus far been reported. This study was designed to investigate whether pulmonary valve grafts maintain in vivo viability, as demonstrated by procollagen synthesis, and whether cryopreservation, histocompatibility, or both affect this property.

Methods: Cryopreserved and fresh rat pulmonary valves were implanted into the abdominal aorta of syngeneic and allogeneic recipients. The grafts and native valves were excised 3 to 21 days after implantation. Valves were sectioned and immunohistochemically stained for procollagen. Computerized morphometry was used to calculate changes in intima, media, and adventitia as a percentage of cross-sectional area of the graft. Procollagen content was graded by semiquantitative methods.

Results: Pulmonary valve grafts had significantly greater collagen density in the intima and adventitia compared with native aortic and pulmonary tissues, but collagen density in the media was similar in all groups. The grafts demonstrated appreciably greater procollagen than the corresponding native valves. These findings were consistent in all grafts (ie, both fresh and cryopreserved, both syngeneic and allogeneic), irrespective of duration of implantation.

Conclusions: Procollagen synthesis occurs in pulmonary valve grafts early after implantation, indicating viability of these tissues. This model of pulmonary valve implantation may have wide applicability to questions of allograft biology. (J Thorac Cardiovasc Surg 2000;120:596-603)
A ortic and pulmonary valve allografts have been widely used for patients with congenital heart defects. Allografts are preferable to the main alternatives, mechanical valves and bioprostheses, because

From the Division of Cardiovascular Surgery, Department of Surgery, Children's Hospital and Regional Medical Center, and the University of Washington, Seattle, Wash.

Received for publication April 4, 1999; revisions requested June 2, 1999; revisions received March 30, 2000; accepted for publication March 31, 2000.

Address for reprints: Flavian M. Lupinetti, MD, Children's Hospital and Medical Center, 4800 Sand Point Way, NE, Seattle, WA 98105 (E-mail: mlupin@chmc.org).

Copyright (C) 2000 by The American Association for Thoracic Surgery

$0022-5223 / 2000 \$ 12.00+0 \quad \mathbf{1 2 / 1 / 1 0 7 6 8 1}$

doi:10.1067/mtc.2000.107681 allografts demonstrate superior hemodynamics, freedom from thrombosis, and reduced risk of infection. Their durability has been questioned, however, and this is a limitation to their use. ${ }^{1,2}$ It is not known what factors determine valve graft longevity. Age of the recipient ${ }^{2-5}$ graft size,${ }^{6}$ immunologic differences, ${ }^{4}$ preservation methods, ${ }^{3}$ and operative technique ${ }^{7}$ are some of the factors suggested as influences on the pathologic fate of the valve. Moreover, differences may exist in the durability of aortic, as opposed to pulmonary, valve grafts. $^{3-5}$ Because of the scarcity of these tissues, both aortic and pulmonary valves must be available if the maximum number of patients is to benefit from their use. Clinical studies that compare the durability of aortic and pulmonary allograft valves are hampered by the numerous confounding variables that make such analy- 
sis complex. Therefore, experimental studies of allograft valves may help to delineate differences in aortic and pulmonary valves in a more well-controlled design. The heterotopic aortic valve implant model has provided a useful approach to questions of valve graft biology. This model has not previously been described with pulmonary allografts, however, in part because of the difficulty of performing the operative preparation with the very delicate pulmonary valve.

This investigation was undertaken to establish the technique of pulmonary valve allograft implantation in the rat model. The model was then used to determine whether synthesis of procollagen, an important structural protein, can be demonstrated in the grafted pulmonary valve. Finally, the effects of cryopreservation and immunologic differences between donor and recipient were studied to understand whether these variables affect procollagen production.

\section{Methods}

Experimental preparation. Heterotopic transplantation of pulmonary valve grafts was performed on the basis of the technique of aortic valve graft implantation described originally by Yankah and colleagues. ${ }^{8}$ Male Lewis rats weighing 100 to $125 \mathrm{~g}$ underwent general anesthesia with intraperitoneal sodium pentobarbital $(65 \mathrm{mg} / \mathrm{kg}$ body weight). Under sterile conditions, the heart and pulmonary arteries were excised and rinsed in $0.9 \%$ saline solution containing heparin $(100 \mathrm{U} / \mathrm{mL})$. The pulmonary valve was excised with a 1-mm cuff of ventricular muscle, and a 5-mm portion of distal artery was attached to permit construction of the anastomoses. Some valves were transplanted immediately, whereas others were transported overnight in vials of heparinized saline solution on ice to CryoLife, Inc (Marietta, Ga) for routine cryopreservation processing. The grafts underwent antibiotic sterilization, immersion in a graded series of dimethyl sulfoxide concentrations to minimize ice crystal formation during cryopreservation, controlled rate freezing at a rate of $-1^{\circ} \mathrm{C} / \mathrm{min}$, and storage in the vapor phase of liquid nitrogen between $-135^{\circ} \mathrm{C}$ and $-196^{\circ} \mathrm{C}$. The valves were returned by overnight air on dry ice and on receipt were stored in the vapor phase of liquid nitrogen until ready for use.

At the time of implantation, cryopreserved valves were thawed by immersion in $37^{\circ} \mathrm{C}$ saline solution and rinsed thoroughly before use. Fresh valves were left in heparinized saline solution while the recipient animal was prepared. Transplant recipients were 200- to 250-g rats of the Lewis (syngeneic) or Brown Norway (strongly allogeneic, RT1 and non-RT1 incompatible) strains. The discrepancy in the size of the donor and the recipient was intended to achieve a more equal diameter of the graft and the donor aorta, each of which was approximately $2 \mathrm{~mm}$. Animals were anesthetized with a single intraperitoneal dose of pentobarbital $(65 \mathrm{mg} / \mathrm{kg}$ body weight). Each recip- ient underwent sterile laparotomy and dissection of the abdominal aorta under a Nikon SMZ-10 stereoscopic zoom microscope (Garden City, NY) with a usual magnification of $14 \times$. The recipient aorta was occluded proximally and distally with vascular clamps and divided. An end-to-end anastomosis of the distal end of the valve graft to the distal end of the native aorta was performed with interrupted 100 Ethilon nylon sutures (Ethicon, Inc, Somerville, NJ). A second end-to-end anastomosis between the proximal end of the graft and the proximal end of the native aorta was constructed with a running 8-0 Prolene polypropylene suture (Ethicon). None of the leaflets were included in the suture line. Instead, a concerted effort was made to allow the possibility that each leaflet remained mobile so that valve coaptation could occur. The presence or absence of leaflet mobility and coaptation is conjectural, however. The distal clamp was then released to check for low pressure flow and leakage followed by the release of the proximal clamp. Patency was assessed, the abdomen was closed, and the animals were allowed to recover.

Rats were allowed to survive for $3,7,14$, or 21 days. Thus, a total of 80 animals were studied, 20 for each of 4 durations of implantation, with 5 each receiving fresh isografts, fresh allografts, cryopreserved isografts, and cryopreserved allografts. Animals were anesthetized at preassigned time intervals with pentobarbital $(80 \mathrm{mg} / \mathrm{kg})$ and exsanguinated by severing the jugular veins. The animals were then slowly perfused through a femoral arterial line at $100 \mathrm{~mm} \mathrm{Hg}$ with $20 \mathrm{~mL}$ of heparinzed saline solution $(100 \mathrm{U} / \mathrm{mL})$ and then with $10 \mathrm{~mL}$ of methyl-Carnoy solution $(60 \%$ methanol with $30 \%$ glacial acetic acid and $10 \%$ chloroform) over a 10 minute period. The native aortic and pulmonary roots and the grafted pulmonary valve were explanted. Specimens were stored for an additional 24 hours in methyl-Carnoy solution before being prepared for immunohistochemistry and routine histology.

All animals received humane care in compliance with the "Guide for the Care and Use of Laboratory Animals" published by the National Institutes of Health (National Institutes of Health publication No. 85-23, revised 1985).

Tissue preparation and histologic examination. All specimens were prepared by dehydration in graded alcohols and xylenes and then infiltrated and embedded in paraffin. Serial sections were cut 5- $\mu \mathrm{m}$ thick, positioned on positively charged slides, and baked at $60^{\circ} \mathrm{C}$ for $60 \mathrm{~min}$ utes. Slides were deparaffinized and rehydrated through xylene and graded alcohols to distilled water. Slides were stained with hematoxylin and eosin (for general histology and structure), aniline blue (for collagen), and Weigert's hematoxylin (for elastin). Weigert's hematoxylin was used to delineate the internal and external elastic laminae, which were used for the demarcations between the intima, media, and adventitia.

The areas and composition of the 3 separate regions were quantified by using a computerized morphometric program (Optimas 5.1, Bothell, Wash). Slides imaged on an Olympus light microscope (Lake Success, NY) were carried by a video 
Table I. Relative contribution of collagen to each layer of arterial walls

\begin{tabular}{lccc}
\hline & Native aorta & Native pulmonary artery & Pulmonary graft \\
\hline Intima & & & $2.0 \% \pm 6.4 \%^{*}$ \\
Mean \pm SD & $0.3 \% \pm 1.1 \%$ & $0.1 \% \pm 0.3 \%$ & 0.02 \\
Median & 0.0 & 0.0 & 0.1 \\
$25 \%$ trimmed mean & 0.0 & 0.0 & $4.9 \% \pm 12.5 \%$ \\
Media & & & 0.5 \\
Mean \pm SD & $3.6 \% \pm 10.9 \%$ & $5.9 \% \pm 12.1 \%$ & 0.6 \\
Median & 0.5 & 1.2 & $12.9 \% \pm 17.2 \%{ }^{\dagger}$ \\
$25 \%$ trimmed mean & 0.6 & 1.4 & 6.3 \\
Adventitia & & $18.0 \% \pm 18.5 \%$ & 7.1 \\
Mean \pm SD & $19.5 \% \pm 16.9 \%$ & 9.4 & 12.1 \\
Median & 14.0 & & \\
$25 \%$ trimmed mean & 15.5 & &
\end{tabular}

${ }^{*} P=.02$ versus native pulmonary artery.

${ }^{\dagger} P=.04$ versus native pulmonary artery.

Table II. Relative amount of pulmonary graft comprising media

\begin{tabular}{llll}
\hline & Mean & $S D$ & P value \\
\hline All grafts & $28 \%$ & $17 \%$ & .2 \\
By duration of implant & $34 \%$ & $14 \%$ & $12 \%$ \\
$3 \mathrm{~d}$ & $22 \%$ & $21 \%$ & $18 \%$ \\
$7 \mathrm{~d}$ & $32 \%$ & & .3 \\
$14 \mathrm{~d}$ & $25 \%$ & $17 \%$ & .3 \\
$21 \mathrm{~d}$ & & $15 \%$ & .03 \\
By histocompatibility & $23 \%$ & $19 \%$ & \\
$\quad$ Syngeneic & $34 \%$ & $15 \%$ & \\
$\quad$ Allogeneic & $26 \%$ & $20 \%$ & \\
By graft treatment & $30 \%$ & $17 \%$ & \\
$\quad$ Fresh & & $15 \%$ & \\
$\quad$ Cryopreserved & $22 \%$ & $13 \%$ & \\
By combination treatment/compatibility & $30 \%$ & & \\
$\quad$ Fresh syngeneic & $24 \%$ & $37 \%{ }^{*}$ & \\
$\quad$ Fresh allogeneic & & \\
$\quad$ Cryopreserved syngeneic & & \\
$\quad$ Cryopreserved allogeneic & & \\
\hline
\end{tabular}

${ }^{*} P=.008$ versus fresh, syngeneic.

camera, processed from analog to digital by an Oculus model TCX on board frame grabber (Coreco, Inc, St Laurent, Quebec, Canada), and displayed on a video monitor. Intimal, medial, and advential areas were measured by use of a threshold-based pixel-counting algorithm. Total areas of the graft and relative amounts of collagen staining in the intima, media, and adventitia as a percentage of each layer were calculated. Comparisons of graft to native aortic and pulmonary specimens were made after data were reduced by means of StatView statistical software (Abacus Concepts, Inc, Berkeley, Calif). Among the grafts, the percentage of each cross-sectional area that was the media was also calculated and recorded.

Comparisons were made between groups by analysis of variance with application of the Bonferroni inequality with paired and unpaired $t$ tests as appropriate.
Immunohistochemistry. Slides were deparaffinized in xylene, rehydrated in graded alcohols, pretreated by immersion in $0.1 \mathrm{~mol} / \mathrm{L}$ sodium citrate ( $\mathrm{pH} \mathrm{8.6)}$, and microwaved at high power for 10 minutes. The slides were cooled for 20 minutes at room temperature, washed with $0.1 \mathrm{~mol} / \mathrm{L}$ phosphate-buffered saline solution (PBS), treated with $3 \% \mathrm{H}_{2} \mathrm{O}_{2}$ for 5 minutes to bind endogenous peroxidase, and washed with PBS.

The slides were then incubated in procollagen protein primary antibody (SPI-D8, University of Iowa) diluted 1:20 with $1 \%$ bovine serum albumin in $0.1 \mathrm{~mol} / \mathrm{L}$ PBS (pH 7.5) for 1 hour at room temperature. Slides were washed in PBS and then incubated in horse anti-mouse secondary antibody (Vector Labs, Burlingame, Calif) diluted 1:250 for $30 \mathrm{~min}$ utes at room temperature. Slides were washed in PBS and then incubated in avidin-biotin complex (ABC Elite, Vector 
Labs) for 30 minutes at room temperature. Slides were washed in PBS and incubated in $175 \mathrm{~mL}$ of $0.1 \mathrm{~mol} / \mathrm{L}$ Trisma-HCl-buffered saline solution $(\mathrm{pH} 7.6)$ in $0.1 \mathrm{~mol} / \mathrm{L}$ PBS containing $0.6 \mathrm{~mL}$ of $3 \% \mathrm{H}_{2} \mathrm{O}_{2}$ and $4 \mathrm{mg}$ of diaminobenzedine (Sigma Chemical Co, St Louis, Mo) for 7 minutes at $37^{\circ} \mathrm{C}$. Slides were washed in distilled water, counterstained for 10 seconds in $1 \%$ methyl green (Sigma) at $\mathrm{pH} 5.4$, dehydrated in $95 \%$ and $100 \%$ alcohols, and placed under coverslips.

Hypertrophic human scar tissue was used as a positive immunohistochemical control tissue for procollagen, and staining with either the primary or secondary antibodies deleted was the negative control. Native, nonoperated, pulmonary and aortic valved conduits and native aortic and native pulmonary valved conduits from transplanted animals served as standard controls.

Experimental, standard, and control slides were examined by light microscopy at $250 \times$. Two observers blinded as to specimen source and working independently graded slides by using a 0 to $3+$ scale $(0$, no staining; $1+$, slight staining; $2+$, moderate staining; and $3+$, staining throughout the majority of media).

\section{Results}

Operative outcomes. To obtain the 80 animals used in this study, a total of 120 animals underwent the operative procedure. There were 40 deaths before the time scheduled for euthanasia. Each dead animal was subjected to necropsy. The cause of death was considered to be viral infection in all cases. Pulmonary valve grafts increased to at least double their initial diameter, from $2 \mathrm{~mm}$ at the time of implantation to $4 \mathrm{~mm}$ at the time of explantation. Rupture did not occur, however. In all cases the distal native aorta was pulsatile, suggesting the absence of any important obstruction within the graft or at the anastomotic sites. None of the pulmonary valve grafts were found to have become occluded with thrombus at the time of excision.

Morphology and quantitative histology. Pulmonary arterial walls, both native and graft, were noticeably thinner than aortic specimens. The pulmonary grafts demonstrated substantial dilatation and appreciable intimal thickening, particularly with longer durations of implantation.

The percentage of each layer of the specimen wall composed of collagen is shown in Table I. There were no significant differences in the collagen density of the native aorta and pulmonary arteries. The arterial wall of the pulmonary graft, however, demonstrated significantly increased collagen in the intima and the adventitia. The media of the pulmonary grafts had a collagen density similar to those of the native tissues. There

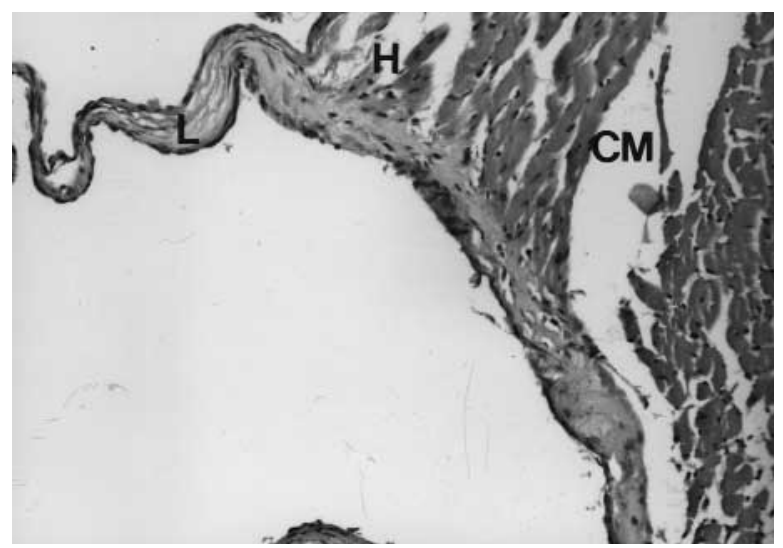

Fig 1. Native pulmonary valve (hematoxylin and eosin stain). $L$, Leaflet of valve; $H$, hinge region of valve; $C M$, cardiac muscle.

were no significant differences among the grafts when analyzed by donor type (syngeneic vs allogeneic), graft treatment (fresh vs cryopreserved), or duration of implantation.

The percentage of each graft that was media is shown in Table II. When analyzed by histocompatibility, graft treatment, or duration of implantation, there were no significant differences between any 2 groups. However, analysis by the combination of histocompatibility and graft treatment demonstrated a significant difference by analysis of variance. Application of the Bonferroni inequality revealed a significantly greater proportion of collagen in the cryopreserved allogeneic group than in the fresh syngeneic group.

Immunohistochemistry. Representative hematoxylin and eosin and immunohistochemical stains for procollagen are shown in Figs 1-8. Procollagen was observed in substantial quantities in the medial region of most transplanted pulmonary valves. This was true of all groups, regardless of valve treatment and histocompatibility, and at all implantation durations. The procollagen antibody stained positively on cells between the elastic lamellae in the medial walls of the grafts. Eighteen of 20 fresh syngeneic and 18 of 20 cryopreserved syngeneic grafts exhibited the presence of procollagen, whereas 14 of 20 fresh allogeneic and 15 of 20 cryopreserved allogeneic valves were positive. In general the distribution of procollagen both in terms of concentration and location was similar to that found in the native tissues. Procollagen staining was observed in the media of only one native pulmonary and no native aortic valve. Procollagen was strongly present in the adventitial regions of all grafts and was absent from the adventitia of all native valves. 


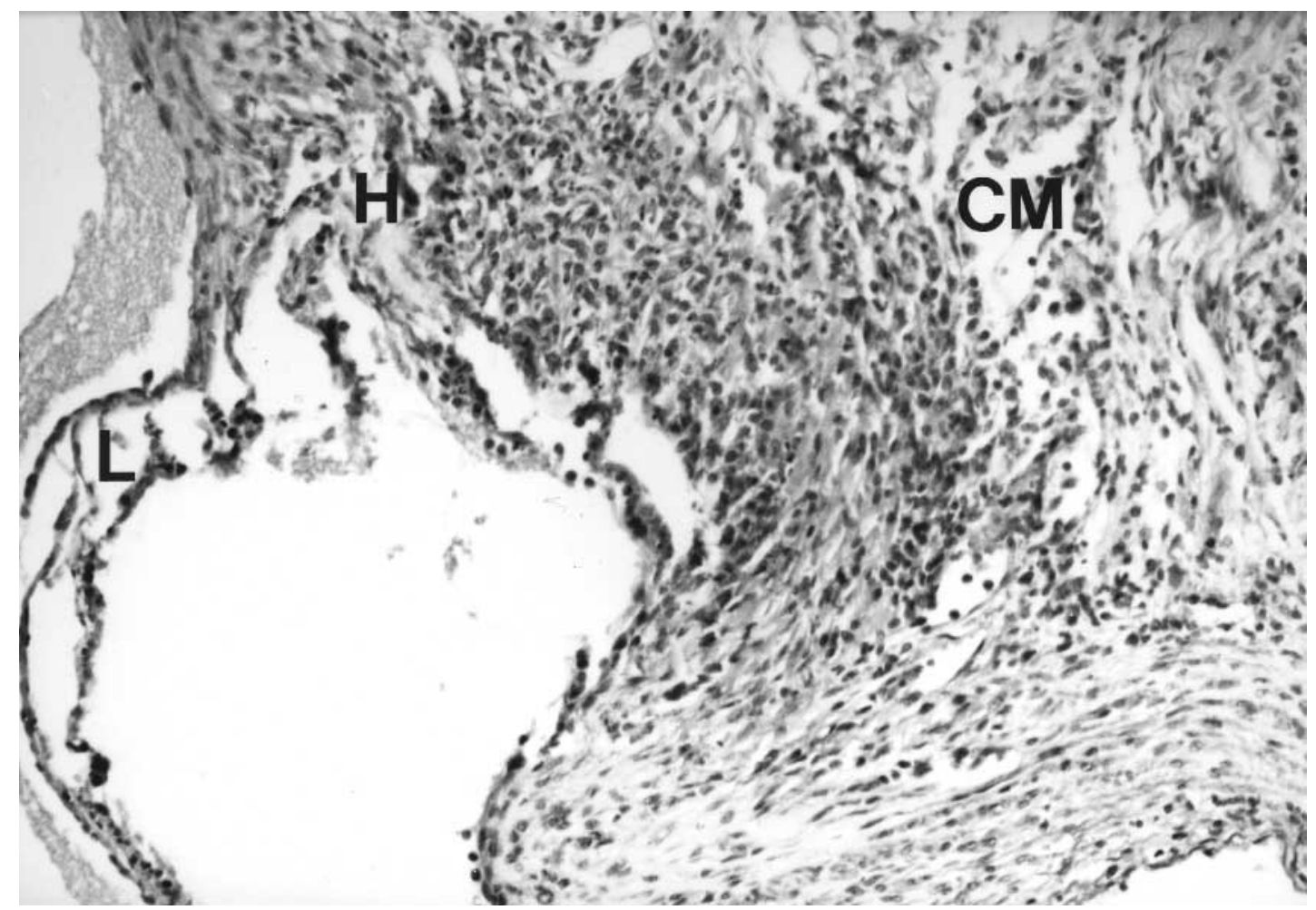

Fig 2. Pulmonary valve graft (7-day cryopreserved allograft; hematoxylin and eosin stain). Increased inflammatory cell response is evident. $L$, Leaflet of valve; $H$, hinge region of valve; $C M$, cardiac muscle.

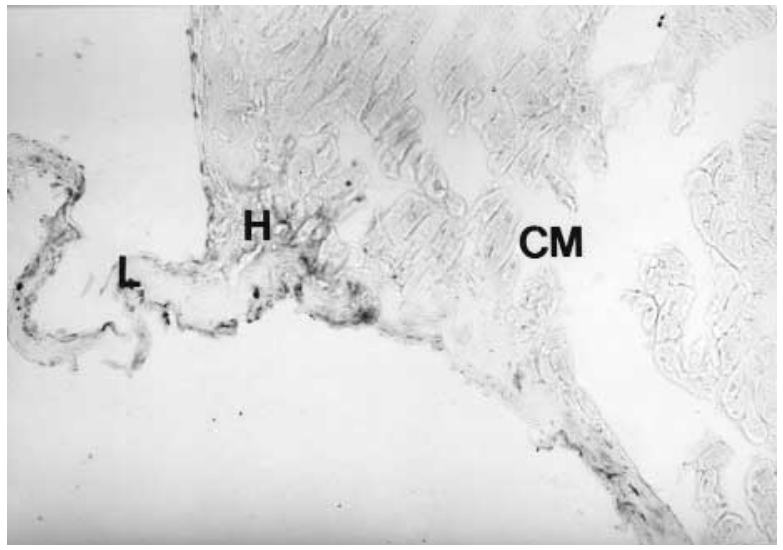

Fig 3. Native pulmonary valve (serial section from tissue block used to obtain Fig 1; immunohistochemical stain for procollagen). Very little procollagen is present. $L$, Leaflet of valve; $H$, hinge region of valve; $C M$, cardiac muscle.

\section{Discussion}

The demonstration of procollagen in the media of pulmonary valve grafts indicates that fibroblasts within the graft are viable and are actively producing an important structural protein. Collagen is the most abun-

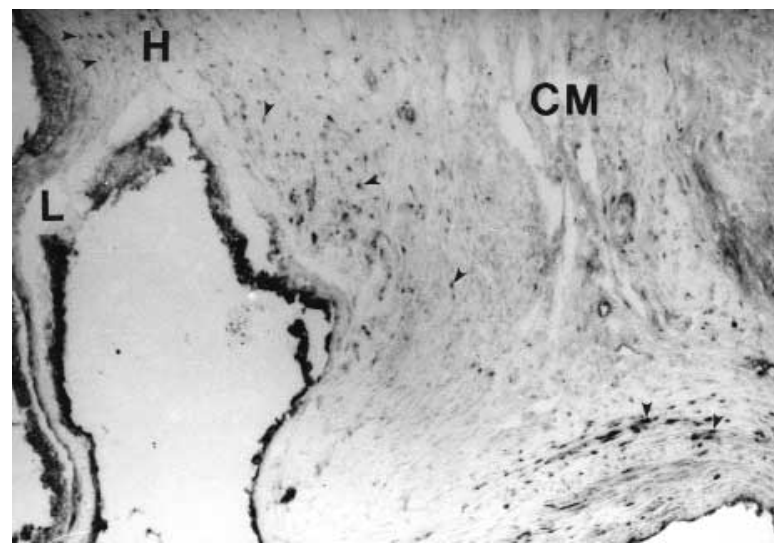

Fig 4. Pulmonary valve graft (serial section from tissue block used to obtain Fig 3; immunohistochemical stain for procollagen). Arrows mark cells positive for procollagen. $L$, Leaflet of valve; $H$, hinge region of valve; $C M$, cardiac muscle.

dant matrix protein and is the one component of the valve graft with the greatest influence on wall strength. The increase in procollagen, the precursor molecule, in the graft suggests that the graft has a capacity for repairing damaged areas and adapting to the increased 


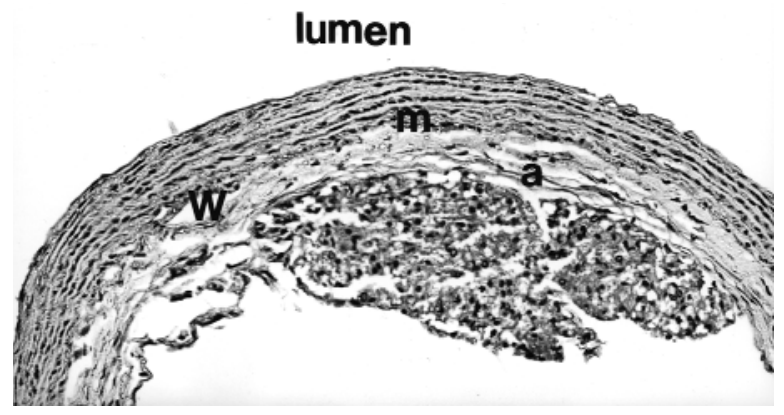

Fig 5. Native pulmonary artery from specimen shown in Fig 1 (hematoxylin and eosin stain). $W$, Wall of artery; $m$, media; $a$, adventitia.

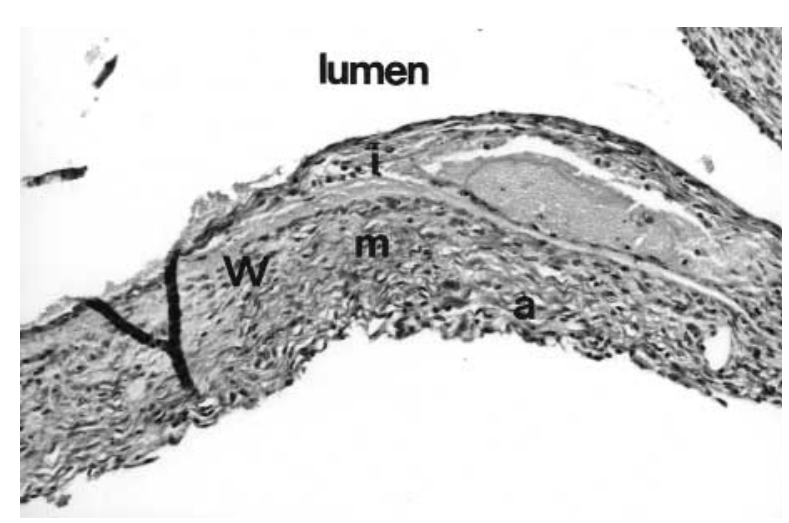

Fig 6. Pulmonary artery graft from specimen shown in Fig 2 (hematoxylin and eosin stain). $W$, Wall of artery; $m$, media, $I$, intima; $a$, adventitia.

hydrostatic pressure of the new environment. This may explain the good immediate clinical results of the use of allografts and the absence of frequent problems related to rupture or aneurysm formation.

The increase in procollagen production observed in pulmonary valve grafts echoes the results previously obtained in this laboratory in a study of aortic valve grafts. ${ }^{9}$ That investigation demonstrated that grafted aortic valves exhibited larger concentrations of procollagen than native aortic valves. As in the present study, cryopreservation and immunologic differences did not appear to substantially affect this procollagen production. This investigation also confirms the previous impression that procollagen deposition was removed from sites of $\alpha$-actin staining. This supports the hypothesis that it is not smooth muscle cells that are the

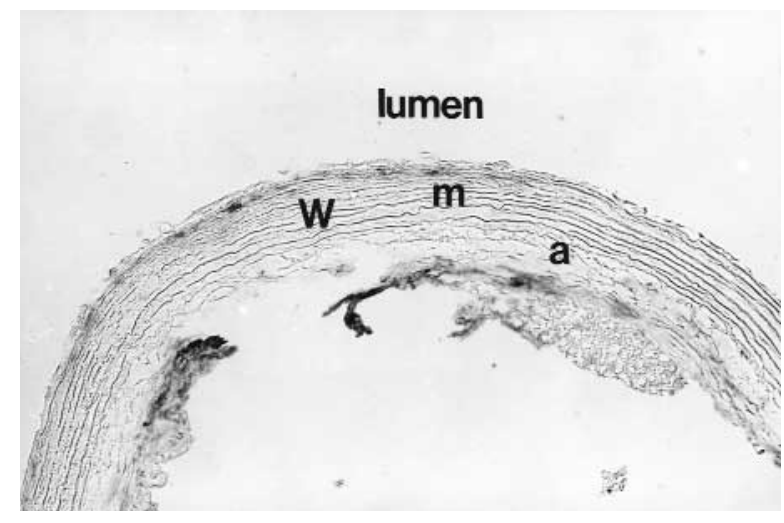

Fig 7. Native pulmonary artery (serial section from tissue block used to obtain Fig 5; immunohistochemical stain for procollagen). Very little procollagen is present. $W$, Wall of artery; $m$, media; $a$, adventitia.

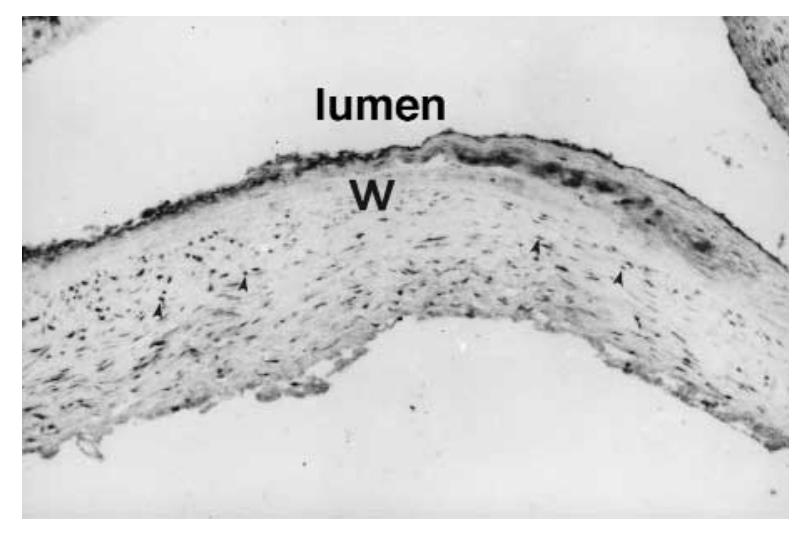

Fig 8. Pulmonary artery graft (serial section from tissue block used to obtain Fig 6; immunohistochemical stain for procollagen). Arrows mark cells positive for procollagen. $W$, Wall of artery.

most likely source of the procollagen. Rather, it is more probable that fibroblasts are the source of the procollagen synthesis. Finally, the present investigation also used histologic morphometry that demonstrated, in a quantitative manner, (1) the increase in intima in the grafts, (2) the similarity of this property at all time points of the study, (3) the similarity of this property regardless of preservation methods or histocompatibility, and (4) the difference between aortic and pulmonary roots.

The production of procollagen may represent a double-edged sword, at least after longer periods of implantation. Longer term results of procollagen synthesis may be a loss of compliance, leading to rigidity, and an obstructive effect. It is interesting that the gross dilatation of the pulmonary grafts in this study was not 
seen in the previous investigation of aortic grafts. ${ }^{9}$ A likely approach to addressing this problem further will require comparison of the present observations with those in human tissues. Ideally, these observations could use Western blot assays for quantitative evaluation of procollagen production, as well as assays for gene expression.

Although extensive experience has been gained with experimental aortic valve grafts, experimental pulmonary valve grafts have been much less thoroughly investigated. Most of the studies that exist have been limited to observations of the mechanical properties of the valve. Using a biomechanical approach, Gorczynski and associates ${ }^{10}$ concluded that fresh pulmonary valve leaflets exhibited a 300\% increase in normalized tensile strength when compared with aortic valve leaflets in swine. David and associates ${ }^{11}$ demonstrated similar stress to failure of both aortic and pulmonary valve cusps. Gerosa and colleagues $^{12}$ also found that the aortic and pulmonary valves displayed similar ultrastructural and biomechanical properties. This group found the pulmonary valve leaflets to be more extensible than aortic leaflets. These studies have been useful in supporting the concept that the pulmonary valve is not inherently weaker than the aortic valve and may be of equal or superior durability when used as a graft.

The heterotopic implant model in the rat offers several advantages for investigating issues of valve graft biology. It is relatively inexpensive and allows extremely precise degrees of immunologic incompatibility between donor and recipient. Because the graft is implanted in an intravascular location, it is exposed to a normal arterial milieu with respect to pressure, $\mathrm{pH}$, and oxygen tension. In the aorta the graft is subjected to mechanical stresses, such as shear stress and pulsatility, like those experienced by the native aortic valve or a pulmonary valve implanted in the aortic position. These forces are probably not identical to those in the orthotopic location because the competence of the native aortic valve prevents this. This issue is important because procollagen synthesis is at least partly regulated by mechanical forces. ${ }^{13}$ Therefore, it is important to note that this study used a potentially competent valve graft. Whether mobility of the leaflets and coaptation actually occur is not known. Type I collagen, the type examined in this study and the most abundant collagen subtype in the heart, is less affected by mechanical stimulation than is type III collagen, the second most abundant type. ${ }^{14}$

Clinical studies that have attempted to distinguish between aortic and pulmonary valve graft durability have produced conflicting results. In the Ross procedure the patient's own pulmonary valve is placed into the aortic position. This procedure has resulted in nearly 30 years of excellent results. ${ }^{15}$ The benefits of this procedure appear to exceed those not only of mechanical valve and bioprosthetic implants but also those of allograft aortic valves. ${ }^{16}$

Pulmonary allografts used in the aortic position have been used successfully, although with considerably less frequency than aortic tissues. ${ }^{12,17-19}$ The aortic allograft is more easily implanted in the aortic position because its greater rigidity makes it easier to achieve proper alignment of the graft with the native outflow tract. The pulmonary allograft, however, can be used with comparable results in terms of immediate hemodynamics, ${ }^{19}$ intermediate-term freedom from complications, ${ }^{17,18}$ and patient survival. ${ }^{12}$

When used as a right ventricle-pulmonary artery conduit, the pulmonary valve allograft has been suggested by some studies to show no better ${ }^{1,20}$ or even worse longevity than aortic valve grafts. ${ }^{3}$ Other centers have found quite different results, with pulmonary allografts exhibiting less calcification ${ }^{5,21,22}$ and better longterm graft survival than aortic valves. ${ }^{4,5}$

The extension of the rat heterotopic model to the pulmonary valve graft has not been reported previously. Even in this laboratory, with extensive experience with the aortic graft implant, the pulmonary valve graft required much practice and resulted in an overall mortality of $33 \%$. The establishment of this model will certainly be useful in addressing other important questions regarding pulmonary valves and the potential differences compared with aortic valves.

\section{REFERENCES}

1. Cleveland DC, Williams WG, Razzouk AJ, et al. Failure of cryopreserved homograft valved conduits in the pulmonary circulation. Circulation 1992;86(Suppl):II-150-3.

2. Chan KC, Fyfe DA, McKay CA, Sade RM, Crawford FA. Right ventricular outflow reconstruction with cryopreserved homografts in pediatric patients: intermediate-term follow-up with serial echocardiographic assessment. J Am Coll Cardiol 1994;24:483-9.

3. Stark J, Bull C, Stajevic M, Jothi M, Elliott M, de Leval M. Fate of subpulmonary homograft conduits: determinants of late homograft failure. J Thorac Cardiovasc Surg 1998;115:506-16.

4. Yankah AC, Alexi-Meskhishvili V, Weng Y, Schorn K, Lange PE, Hetzer R. Accelerated degeneration of allografts in the first two years of life. Ann Thorac Surg 1995;60:S71-7.

5. Bando K, Danielson GK, Schaff HV, Mair DD, Julsrud PR, Puga FJ. Outcome of pulmonary and aortic homografts for right ventricular outflow tract reconstruction. J Thorac Cardiovasc Surg 1995;109:509-18. 
6. Weipert J, Meisner H, Mendler N, et al. Allograft implantation in pediatric cardiac surgery: surgical experience from 1982 to 1994. Ann Thorac Surg 1995;60:S101-4.

7. Kobayashi J, Backer CL, Zales VR, Crawford SE, Muster AJ, Mavroudis C. Failure of the Hemashield extension in right ventricle-to-pulmonary artery conduits. Ann Thorac Surg 1993;56:277-81.

8. Yankah AC, Dreyer W, Wottge HU, Muller-Rucholtz W, Bernhard A. Kinetics of endothelial cells of preserved aortic valve allografts used for heterotopic transplantation in inbred rat strains. In: Bodnar E, Yacoub M, editors. Biologic and bioprosthetic valves. New York: Yorke Medical Books; 1986. p. 73-84.

9. Lupinetti FM, Kneebone JM, Rekhter MD, Brockbank KGM, Gordon D. Procollagen production in fresh and cryopreserved aortic valve grafts. J Thorac Cardiovasc Surg 1997;113:102-7.

10. Gorczynski A, Trenker M, Anisiurowicz R, et al. Biomechanics of the pulmonary autograft valve in aortic position. Thorax 1982;37:535-9.

11. David H, Boughner DR, Vesely I, Gerosa G. Is the pulmonary valve a mechanically suitable replacement for the aortic valve? Can J Cardiol 1992;8(Suppl B):135B.

12. Gerosa G, Ross DN, Brucke PE, et al. Aortic valve replacement with pulmonary homografts: early experience. J Thorac Cardiovasc Surg 1994;107:424-37.

13. Sinning AR, Lepera RC, Markwald RR. Initial expression of type I procollagen in chick cardiac mesenchyme is dependent upon myocardial stimulation. Dev Biol 1988;130:167-74.

14. Carver W, Nagpal ML, Nachtigal M, Borg TK, Terracio L.
Collagen expression in mechanically stimulated cardiac fibroblasts. Circ Res 1991;69:116-22.

15. Chambers JC, Somerville J, Stone S, Ross DN. Pulmonary autograft procedure for aortic valve disease: long-term results of the pioneer series. Circulation 1997;96:2206-14.

16. Jones TK, Lupinetti FM. Comparison of Ross procedures and aortic valve allografts in children. Ann Thorac Surg 1998;66:5170-3.

17. Mair R, Harringer W, Wimmer-Greinecker G, et al. Aortic valve replacement with cryopreserved pulmonary allografts: five years' follow-up. Ann Thorac Surg 1995;60:S185-8.

18. Konertz W, Tandler R, Hasfeld M, Fahrenkamp A, Breithardt G, Schled HH. Aortic valve replacement with cryopreserved pulmonary allograft. J Card Surg 1994;9:43-9.

19. Lupinetti FM, Lemmer JH Jr, Ferguson DW, Stanford W, Behrendt DM. Aortic valve replacement with pulmonary or aortic allografts. Circulation 1991;84(Suppl):III-89-93.

20. Hawkins JA, Bailey WW, Dillon T, Schwartz DC. Midterm results with cryopreserved allograft valved conduits from the right ventricle to the pulmonary arteries. J Thorac Cardiovasc Surg 1992;104:910-6.

21. Albert JD, Bishop DA, Fullerton DA, Campbell DN, Clarke DR. Conduit reconstruction of the right ventricular outflow tract: lessons learned in a twelve-year experience. J Thorac Cardiovasc Surg 1993;106:228-36.

22. Shaddy RE, Tani LY, Sturtevant JE, Lambert LM, McGough EC. Effects of homograft blood type and anatomic type on stenosis, regurgitation and calcium in homografts in the pulmonary position. Am J Cardiol 192;70:392-3. 